\title{
HIV/AIDS: The Zimbabwean Situation and Trends
}

\author{
Duri Kerina ${ }^{1, *}$, Stray-Pedersen Babill², Muller $\mathbf{F}^{3}$ \\ ${ }^{1}$ Department of Immunology, University of Zimbabwe, Harare, Zimbabwe \\ ${ }^{2}$ Division of Women and Children, Oslo University Hospital, Rikshospitalet and Institute of Clinical Medicine, University of Oslo, \\ Oslo, Norway \\ ${ }^{3}$ Department of Microbiology, University of Oslo and Oslo University Hospital, Rikshospitalet, Oslo, Norway \\ *Corresponding author: tkduri@yahoo.co.uk
}

Received January 03, 2013; Revised February 13, 2013; Accepted February 16, 2013

\begin{abstract}
Although there are many Zimbabwean published manuscripts reporting on different HIV/AIDS research areas on what has been happening over the years concise national reviews are rare yet such reports are not only important to the respective researchers and policy makers of the native country but are also of great value to potential donors and/or collaborators who may wish to have a quick and deep understanding of disease burden and trends of the nation they may wish to work with. Recent data from general population surveys point to a remarkable decline in the HIV prevalence attributed mainly to changes in sexual behavior and to some extent to effective preventive programmes such as male circumcision, prevention of mother to child transmission of the virus (PMTCT) including improved access to antiretroviral therapy among the infected that has consequently reduced transmission at population level. This review seeks to give a simple and clear Zimbabwean HIV/AIDS perspective detailing the geographical, demographical, social economic status including HIV related legal aspects that could have shaped the observed disease burden and trends. Milestones, impact, and challenges around the control of the HIV/AIDS pandemic will be discussed.
\end{abstract}

Keywords: HIV/AIDS, Trends, socio-economics, Zimbabwe

\section{Background}

\subsection{Geographic Profile of Zimbabwe}

Zimbabwe lies north of the Tropic of Capricorn between the Limpopo and Zambezi rivers. Situated in Southern Africa, it is a landlocked country covering an estimated area of $390,784 \mathrm{~km}^{2}$. Zimbabwe borders Zambia, Mozambique, Botswana and South African to the, north, east, west and south, respectively. A narrow north-western border is also shared with Namibia at the Caprivi Strip as shown in Figure 1 below. For administrative purposes the country is divided into ten provinces which are further divided into 58 districts. Zimbabwe attained its independence from the British in April 1980 after a protracted armed guerilla struggle. Since then until the late 1990 s all sectors of the economy performed well.

Southern Africa Zimbabwe

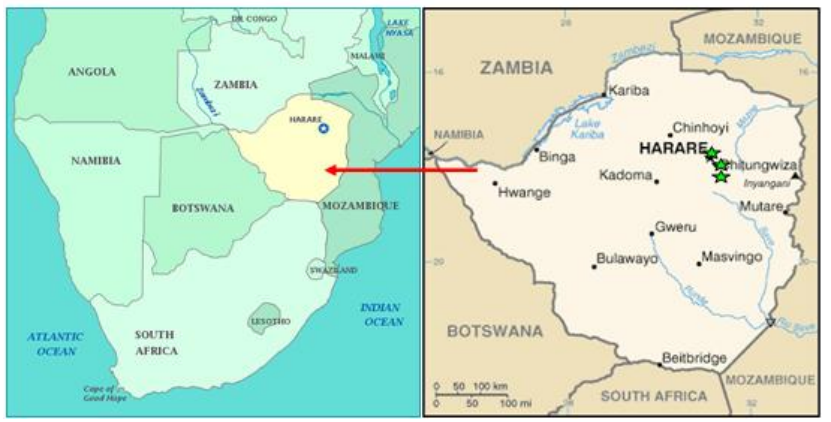

Figure 1. Geographical Location of Zimbabwe
Zimbabwe boasts of abundant natural resources that include 9 million hectares of potentially arable land and more than 5 million hectares of forests, national parks, and wildlife estates. The country is adored for its extensive and varied mineral resources such as platinum, gold, asbestos, coal, nickel, iron, copper, lithium, not to mention precious gems such as emeralds and diamonds. There are adequate supplies of both the surface and ground water which are not only enough for domestic and industrial uses but that can also be harnessed for generation of hydro-electric power and irrigation of crops [1]. The economy is diversified but biased towards agriculture, mining and tourism. However, despite the abundance of these natural resources the country has been riddled with profound socio-economic and political challenges in the last decade that nearly drove the economy into oblivion had it not been for the government of national unity (GNU) signed in February 2009 by the three major feuding political parties.

\subsection{Population Size and Trends}

A national census is carried out every ten years since 1931. Currently the 2012 census is on-going. The population has been doubling almost every 20 years. According to the previous 2002 census, Zimbabwe had 11.6 million people, 1.2 million more than in 1992 and 4.2 million more than in 1982 [1]. There are discussions to the effect that the 2002 census excluded about three million Zimbabweans who are economic refugees in the Diaspora. About $70 \%$ of the population lives in the rural areas. Africans constitutes about $98 \%$ of the population. Major ethnic groups are the Shona $(82 \%)$ and Ndebele (14\%) 
tribes with the rest being other ethnic minorities as shown in Table 1 below. Zimbabwe is generally a Christian nation and in some instances mixed with traditional beliefs. About $1 \%$ of the population is Muslim. Proudly the national literacy rate is very high $(94 \%)$ with almost all the urbanites being literate. The 2002 population pyramid had a wide but tapering base depicting a population experiencing a decline in fertility probably due to previous socio-economic hardships and/or the current HIV/AIDS pandemic. On a lighter note, the current total fertility rate for Zimbabweans is 4.1 children per woman slightly higher than the previous the one in 2005-6 [2].

Table 1. Trends of Selected Demographic Indicators in Zimbabwe

\begin{tabular}{|l|l|l|}
\hline Indicator & 1992 Census & 2002 Census \\
\hline Total Population (thousands) & 10,412 & 11,632 \\
\hline Distribution by Ethnic group (\%) & & \\
\hline Africans & 98.8 & 99.3 \\
\hline European & 0.8 & 0.4 \\
\hline Coloured & 0.3 & 0.2 \\
\hline Asians & 0.1 & 0.1 \\
\hline Distribution by age group (\%) & & \\
\hline $0-14$ & 45.1 & 40.6 \\
\hline $15-64$ & 51.3 & 55.0 \\
\hline$\geq 65$ & 3.3 & 4.0 \\
\hline Not Stated & 0.3 & 0.4 \\
\hline Crude Birth Rate & 34.5 & 30.3 \\
\hline Crude Death Rate & 9.5 & 17.2 \\
\hline Life Expectancy & 61.0 & 45.0 \\
\hline Source: Central Statistical Office, 2002 &
\end{tabular}

National surveys which involve HIV testing called Demographic and Health Surveys (DHS) are conducted every five years with the primary objective to provide current information and statistics for policymakers, planners and researchers on population key health indicators such as but not limited to fertility levels, sexual activity, mortality rates and HIV infection. Though quite expensive, such surveys offer nationally representative statistics as more than 11000 randomly chosen households are enumerated and over 43000 individuals interviewed. According to the 2010-11 DHS, females represented 53\% of the population whilst the proportion of children under 15 and senior citizens above 65 years of age were $43 \%$ and $5 \%$, respectively [2]. Median ages at first marriage among women and men were 19.7 and 24.8 years, respectively. Up to eleven percent of married women were married to men who were already in polygamous unions [2].

\subsection{Socio-economic Conditions}

Zimbabwe has been the only country in the Southern Africa Development Community (SADC) region experiencing a negative economic growth rate following political and economic crisis since 2000. The economy deteriorated from one of Africa's strongest to the world's worst with the official inflation rate estimated at more than $1000 \%$ in 2006 [3]. Excessive demand for foreign currency pushed the inflation rate from 231 million percent in July 2008 to more than 79.6 billion percent per month, thus translating to an annual inflation rate of over
90 sextillion $\left(10^{21}\right)$ percent [4]. Zimbabwean currency of billions denomination, as shown in Figure 2 below, was literally not worth the paper on which it was printed.

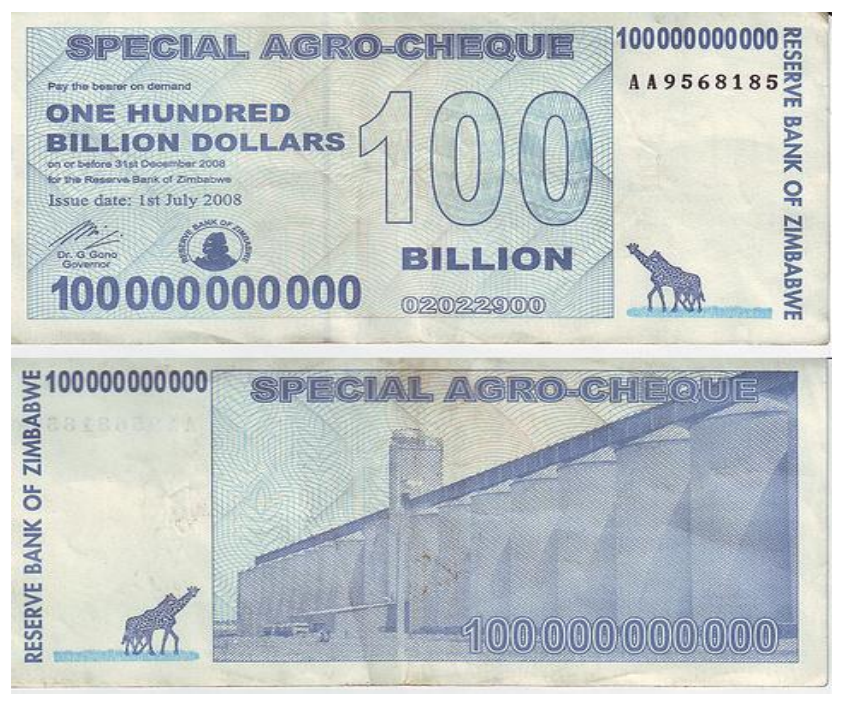

Figure 2. Zimbabwean Currency during Hyperinflation period

The country experienced acute shortages of foreign currency, food stuffs, liquid fuels, electricity, medical equipment, and drugs. With over $80 \%$ formal unemployment levels, the informal sector has been growing stronger and stronger over the years. Compounded by sanctions, hyperinflation has been the major problem in the past decade until April 2009 when the new coalition government suspended the use of local currency in favor of multi-foreign currencies. Economic challenges encountered in the period 2000-2008 led to abject poverty. Coping strategies to mitigate food and foreign currency shortages were devised. Most jobless Zimbabweans including women resorted to cross border trading with regional and inter-continental countries thereby exposing themselves to sexual and other forms of abuse during the execution of their dealings [5]. As the economy deteriorated further farmers struggled to recover from the economic downturn causing inevitable food shortages. Low remuneration not commensurate with the then prevailing economic conditions made working in the health sector non-conducive leading to low morale. Consequently, there has been massive brain-drain of experienced professionals in all sectors of the economy among the general population to unprecedented levels. Challenges associated with staff attrition in the health sector negatively impacted on the quality and coverage of HIV/AIDS health programs.

\subsection{Health Care}

Soon after independence, the Zimbabwean government adopted national policies that benefited the black majority such as access to free education and health care. One of the salient policy tenets in post independent Zimbabwe was "Health for all by year 2000". To this end, the government built over 240 new health centres and refurbished and upgraded over 500 pre-existing centres. The Zimbabwean's healthcare system was so good such that $85 \%$ of the population lived within 10 kilometers of a health care facility. Lives of most Zimbabweans improved dramatically as depicted by key health indicators such as life expectancy, maternal and infant mortalities. Sadly, 
these early socio-economic gains were short lived as maternal mortality rate increased from 283 per 100000 in 1994 to 555 deaths per 100000 live births in 2005 [6] and to 960 deaths per 100000 live births in 2010 [2]. Infant mortality rate rose from 50 per 1000 live births in 1990 to 57 per 1000 in 2010[2,7]. Mortality rates more than tripled among adults, sky-rocketing from 286 per 1,000 in 1990 to 751 per 1000 in 2006[7]. This drastic fall in vital health statistics was partly due to the diminished access to healthcare, brain-drain and closures of public hospitals and prohibitive medical care costs complicated by foreign currency shortages. Most distressing was the dramatic fell of the average life expectancy at birth from 60 years in 1990 to about 40 years in 2006 as shown in Figure 3. Malnutrition and high HIV prevalence were major factors that precipitated the decline of life expectancy $[8,9,10,11,12,13]$.

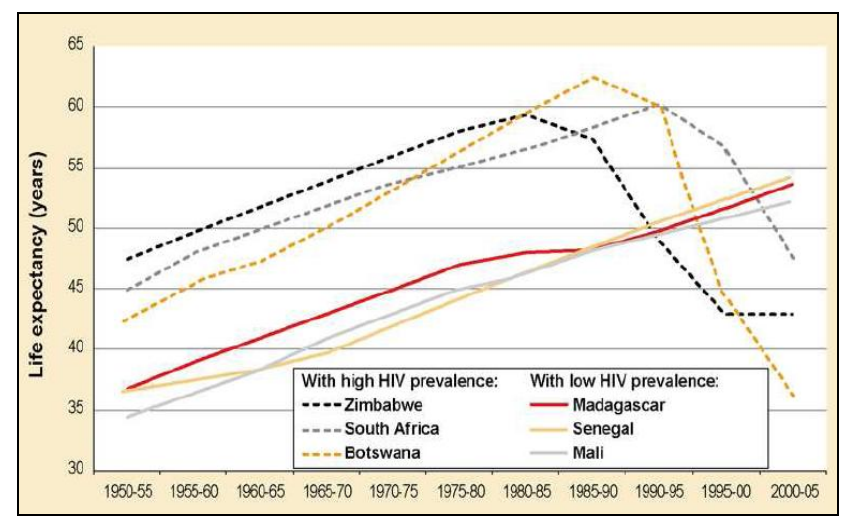

Figure 3. Trends in life expectancy in Zimbabwe relative to other African countries [14]

Encouragingly, more recent figures show that the average life expectancy is up to about 48 years [15]. The current improved health delivery system has seen the welfare of most Zimbabweans improve through economic recovery, increased access to antiretroviral therapy as well as better nutrition [16].

\section{Introduction: The Zimbabwean HIV/AIDS Situation}

\subsection{HIV/AIDS: The Beginning}

The first AIDS case was reported in Zimbabwe in 1985 [17]. Since then more patients began to present with illnesses suggestive of HIV infection. Young adults presented with severe respiratory infections, herpes zosters, persistent generalised lymphadenopathy and diarrhea associated with weight loss $[18,19]$. Children were seen who seemed to be suffering from malnutrition but whose socio-economic backgrounds were inconsistent with poverty [10,12]. Sadly, such patients failed to respond to standard nutritional and conventional medical treatments, suggesting an immunodeficiency condition.

\subsection{HIV in Blood Donors}

The foregoing observation was the basis for the introduction of routine HIV-1 testing of donated blood and blood products in August 1985 by the National Blood Service Zimbabwe (NBSZ). Since then, HIV testing has been available to clinicians [19]. HIV-1 sero-prevalence amongst blood donors by then was $2 \%$. Ten years later, the HIV sero-prevalence amongst blood donors had arisen to $8.8 \%$ with a sero-incidence of 2.1 per 100 person-years and being highest among married first-time blood donors of 21-45 years of age [20,21]. From 1995 onwards, HIV testing included screening for both the two types, HIV-1 and HIV-2 [22]. As of 2010, NBSZ reported an HIV-1 prevalence of $0.74 \%$, a slight decline from $0.77 \%$ in 2009 [23]. Within this healthy blood donor population the hepatitis B virus (HBV) and syphilis sero-prevalence were $0.97 \%$ and $0.68 \%$, respectively [23]. Over the years there has been a remarkable decline in HIV-1 prevalence among blood donors as shown in Figure 4 below.

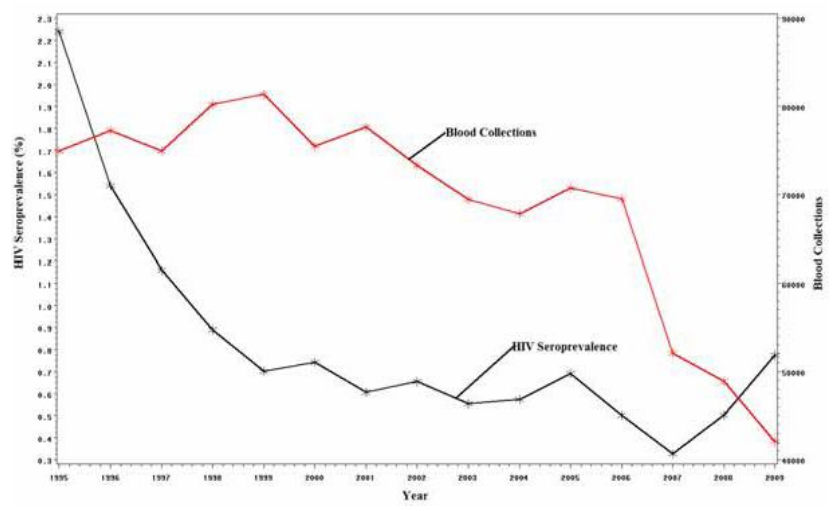

Figure 4. HIV Sero-Prevalence Trends among Blood Donors (19952009) [23]

\subsection{HIV-1 Trends and Distribution in the General Population}

Following the diagnosis of the first case of HIVinfection in the Northern district of Hurungwein 1986, a local hospital based surveillance system was introduced to monitor the spread of the epidemic [24]. This was before the official notification system included the HIV syndrome. In this district AIDS cases increased exponentially from 19 in 1986 to 290 in 1987, 433 in 1988, and 145 during the first quarter of 1989 [24]. As early as 1987 the prevalence had shot up to $3.2 \%$ and interestingly all infections were found in the 17-30 years old group [25]. A cross sectional hospital-based study screening for STIs amongst adult volunteers at Murehwa rural district hospital, $100 \mathrm{~km}$ north east of Harare in 1990 demonstrated a 50\% HIV-1 sero-positivity amongst adults with STIs [26]. This fast growing HIV epidemic became a major threat to the health and development of the district, nation, region and the world at large, raising many questions. Where did this infection come from and why so many cases in a very short space of time? Sadly in Zimbabwe, there was so much denial by the government until 1990 when HIV/AIDS issues were debated in the public domain.

Routine sentinel surveillance of pregnant women attending antenatal care clinics commenced in 1990. In the year 1990 the antenatal clinic (ANC) based HIV-1 surveillance was launched and prevalence exceeded $10 \%$. On a positive note, the HIV-1 prevalence among women attending ANC declined from around $32 \%$ in 2000 to about $16 \%$ in 2011 [27,28,29,30,31,32,33,34,35] Data from such surveillance has provided the estimated HIV prevalence rates for the adult population. The country's 
national estimate for HIV prevalence amongst adults stands atabout $13.7 \%$ down from $26 \%$ around 1999 [36].

\subsection{Gender and HIV/AIDS}

The coming together of traditional culture with the colonial legacy of men migrating to cities for employment leaving behind their spouses has influenced family structures and sexual relations. [37]. However, for many women, sexual relations with men are either within marriage for procreation or outside wedlock linked to economic and social survival [38,39]. In the later scenario sexually transmitted infections including genital ulcers are more common that consequently facilitate transmission of HIV [40,41].In Zimbabwe just like the rest of Africa young women continued to bear the brunt of the pandemic. Promisingly, $34 \%$ of women and $21 \%$ of men tested for HIV and received their results in the 2010-11 DHS relative to just $7 \%$ for both sexes in the 2005-6 DHS. The 2010-11 DHS included HIV testing of 7000 women and 6000 men. HIV prevalence peaked to $29 \%$ in the $30-39$ age group contrary to $30 \%$ prevalence amongst males in the 45-49 age group ${ }^{2 .}$ One percent of the women and $11 \%$ of men of the 15-49 age group reported having sex with at least two partners during the past year of which $48 \%$ and $33 \%$ of the women and men, respectively reported use of a condom during their last sexual intercourse. All in all 15\% of these adults were HIV positive relative to $18 \%$ in the 2005-6 DHS. HIV prevalence was $18 \%$ and $12 \%$ for women and men respectively (Figure 5).

\section{HIV Prevalence}

\section{Women 15-49 an 15-49 $\quad$ Total 15-49}

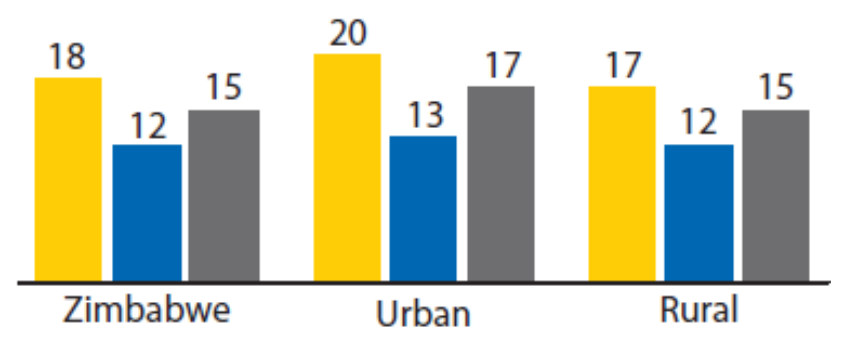

Figure 5. HIV-1 Prevalence among the 15-24 years old by Gender and place of Residence [2]

No clear relationship between level of education and HIV prevalence has been observed among women [2]. Conversely, HIV prevalence has been shown to decrease with increased education amongst men 2. Interestingly, no clear relationship between wealth and HIV prevalence among both women and men have been observed [2]. Circumcised men in the age group 15-49 have been shown to be slightly more likely to be HIV positive relative to their uncircumcised counterparts [2]. Thus, sadly circumcision may be giving a false sense of HIV protection among these men.

\subsection{HIV/AID by Province}

The epidemic at country level is widely heterogeneous in nature with HIV prevalence in small towns, farming estates and mines located in rural areas (22\%) exceeding that in the major cities $(14.5 \%)$. Significant variations in the HIV-1 prevalence of the pandemic across the country is also observed at provincial level with Matabeleland
South, bordering Botswana, having the highest prevalence and ironically Harare, the capital city, the lowest as shown in Figure 6 below.

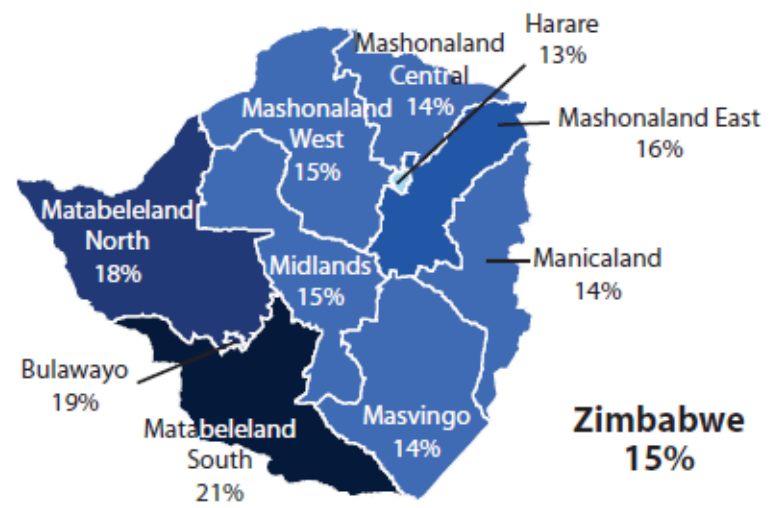

Figure 6. HIV Prevalence by Province in Zimbabwe [2]

Recent statistics amongst 2700 co-habiting couples has shown that in $79 \%$ of the cases both partners are HIV sero-negative [2] whilst in $10 \%$ of the couples both partners are HIV sero-positive. Interestingly, $11 \%$ of couples are discordant, that is, one partner is infected with HIV and the other is not [2].Thus, sexual contact with an HIV infected person represents only a necessary, but not sufficient, condition for HIV transmission through sex suggesting that other cofactors may be central in fueling the HIV epidemic.Studies have observed a synergistic relationship between HIV and co-infections including other environmental factors that could be possible cofactors for HIV-1 acquisition and/ or transmission $[42,43,44,45]$.

\subsection{HIV/AIDS in Children}

Mother to child transmission (MTCT) of HIV is a huge problem in Zimbabwe which has become the major cause of infant and child mortality [35]. It is the most significant $(90 \%)$ source of HIV infection in children below the age of 15 years. Without any PMTCT intervention, about a third of the HIV infected women will pass the virus to their babies. Most infections therefore occur during labour, delivery and breastfeeding. The goal of Zimbabwe PMTCT is to reduce PMTCT of HIV infection, thereby leading to reduction of infant morbidity and mortality. In 2009, $56 \%$ of HIV-positive pregnant women received antiretrovirals for PMTCT; only $35 \%$ of HIV-exposed infants received prophylactic ARVs for PMTCT. Between 1980 and 2005, among 10 million children born in Zimbabwe, a cumulative 504,000 were vertically infected with HIV [46]. As of 2010 it is estimated that about 120000 children between the ages of $0-14$ are living with HIV/AIDS of which $3.4 \%$ of children aged 10 years are long-term survivors following MTCT [47]. With continued efforts to reach women with PMTCT services, and renewed commitment to addressing gaps in antenatal care access and delivery by a skilled attendant, national targets for PMTCT can be met.

\subsection{HIV-1 in the Military Population}

Generally militaries are reluctant to divulge figures on HIV prevalence for security reasons. However, Zimbabwe Defense Forces' (ZDF) figures are believed to be high 
$[48,49]$. The risky behaviour of military personnel compounded by the high HIV-1 sero-prevalence within this population has been a cause for concern [50,51]. ZDF personnel have been actively involved in peace keeping mission in Somalia, Rwanda, and Angola. Controversially, they have been deployed in the Democratic Republic of Congo (DRC) and Mozambique to fight civil war in support of the ruling regimes alongside other troops from Angola and Namibia. These external missions, whether offensive in nature or peace keeping have had a bearing on the transmission of HIV/AIDS within the armed forces to and from the civilian population both at home and abroad [49]. There has been a deep concern regarding the possibility of ZDF personnel introducing new infections into the country inclusive of HIV-1. There are discussions to the effect that the HIV-1 epidemic originated from multiple introductions into the country in the late 1970s during the demobilization phase of war corresponding to rapid influx of native military personnel from neighbouring countries and abroad [52].

\subsection{HIV/AIDS \& Legislation}

HIV/AIDS stigma does not only devastate the familial, social, and economic lives of individuals, but has also been a major obstacle in accessing prevention and care [53]. AIDS stigma has been an impediment to the uptake of voluntary counseling and testing (VCT) of HIV [54]. However, with the advent of antiretroviral therapy that conceals or treats visible signs and symptoms associated with AIDS the issue of stigma has improved remarkably. In Zimbabwe discrimination of HIV positive people is prohibited under National HIV and AIDS Policy of 2000 and the Statutory Instrument (SI 202) of 1998 which also prohibits HIV screening for purposes of employment. The country has not able to fund its response to HIV/AIDS through domestic and international sources of finance. It was against this background that the government of Zimbabwe used the Presidential Powers (Temporary) Regulations to declare HIV/AIDS a national disaster. This consequently legally empowered Zimbabwe to manufacture antiretroviral generic drugs locally. Criminal Law (Codification and Reform) Act 23 of 2004 is an extraordinary piece of legislation which makes it a crime for a person who knows that he or she has HIV to infect another, even between husband and wife. However, some authors summarise it all by saying "that such a law creates a crime not of effect and consequence, but of fear and possibility" [55]. They go on to argue that enacting of HIV-specific laws to criminally punish transmission of, exposure to, or non-disclosure of HIV, is counter-active to good public health conceptions and ironically unacceptable to elementary human rights principles.

\section{Mitigation Strategies}

As part of the nation's attempts to raise funds for the control and management of HIV/AIDS the Government of Zimbabwe introduced the National AIDS Trust Fund (also called AIDS Levy) which entails collection of $3 \%$ of all taxable individuals and corporates incomes to fund HIV/AIDS programmes. There has been introduction and integration of family planning with HIV/STI and maternal health services voluntary counseling and testing (VCT), prevention of mother-to-child transmission (PMTCT) including primary care to identify the infected individuals with the intention of preventing both horizontal and vertical transmissions. Widowhood plays an important role in the transmission and has been associated with 8$17 \%$ of all HIV cases [56]. As such family structures of traditional intra-and intergenerational coping mechanisms such as the levirate, whereby a widow is remarried to a close family member of the deceased husband are now being discouraged [57].

The epidemic in Zimbabwe is also believed to be declining as result of the impact of the prevention programmes such as male circumcision.Since 2009, Zimbabwe has provided circumcision to adult and adolescent men through a collaborative effort between the government and technical agencies with the aim to reach 1.2 million $15-29$ year-olds by 2015 [58,59]. The steady HIV-1 prevalence decline is also attributed to several factors such as behaviour change, condom use or high mortality rate of the infected [60,61,62]. The severe economic decline in the last decade has played a considerable role in sexual behavior change, particularly partner reduction particularly amongst urban men [34]. With the gross domestic product in Zimbabwe declining by about $40 \%$ many men reported having less disposable income and as such their ability to purchase sex or maintain multiple sexual relationships was reduced $[62,63]$. Decline could also be due to the early adoption of a home-based care policy by the Zimbabwean government's which also inadvertently accelerated the process of behavior change. It has been hypothesized that when AIDS patients die at home, an experience that offers an opportunity among close family members and friendsto have direct confrontation with AIDS morbidity and mortality, is more likely to instill fear of acquiring HIV/AIDS compared to a situation when they are primarily cared for in health institutions [64].

\subsection{Access to ART}

Antiretroviral therapy (ART) has substantially reduced HIV-related morbidity and mortality worldwide. A growing body of empirical evidence and mathematical modeling suggests that expanded ART use may also prevent population-level transmission of HIV [65]. One million two hundred thousand people are living with HIV/AIDS of which 200000 are children under 15 years. Access to antiretroviral therapy (ART) is quite limited in Zimbabwe. With over 300,000 people in need of ART, Zimbabwe is among the 20 countries identified by the World Health Organization (WHO) as having the highest unmet needs for ART. On a positive note, access to treatment has mitigated the stigma and fatalism associated with HIV infection and AIDS thereby enhancing uptake of VCT. Despite many challenges, the majority of HIV/AIDS patients are accessing HIV care. Development of referral tools and decentralization of CD4 testing to clinics and with nurses now initiating ART have all resulted in improved access to ART. Maintaining millions of people on treatment throughout their lifetimes is not sustainable and hence the importance of prevention strategies needs not to be over-emphasised.

As ART is prolonging the life expectancy for HIVinfected persons with studies showing that considerable proportion of HIV-positive women and men desire to have 
children in the future $[66,67]$. Therefore integrating sexual and reproductive health care into HIV services cannot be over emphasized for the HIV infected women to make informed choices about their reproductive lives. More recently some women living with HIV/AIDS have recently reported to the media that they were sterilized without their consent or were coerced to consent during the peak of the epidemic and now they are contemplating suing the clinicians for misleading them as they now wish to conceive with the coming on board of the effective PMTCT programs. Most patients on ART also use traditional herbal remedies to supplement treatment $[68,69,70]$.There is a gap in knowledge on the safety of concurrent use of the traditional herbal remedies and antiretroviral drugs. Although ART has transformed HIV1 infection from a fatal disease into a more chronic manageable condition there are still concerns regarding the general safety profiles of these antivirals which brings us to another exciting field of research of therapeutic HIV1 vaccines. However, the main challenge for therapeutic vaccination is to elicit strong and efficient CD4+ and CD8+ T-lymphocyte responses that would allow discontinuing ART after viral suppression to circumvent toxicity drawbacks associated with these drugs.

\subsection{Impact of HIV/AIDS}

Mortality began to rise in urban areas of Zimbabwe in the late 1980s and in rural areas in the early to mid-1990s [71]. 2005/6 DHS indicated that the probability of death before age 60 years among those who survived to age 15 years increased from 30 and $21 \%$, for men and women, respectively, in the late 1980 s to about $70 \%$ for men and $60 \%$ for women, by the early 2000s [27,72,73]. In 2009 alone 83,000 HIV/AIDS related deaths were recorded. The number of children orphaned that is, a child with one or both parents dead due to HIV/AIDS in Zimbabwe remains high $(20 \%)$. The approximate number of such orphans is estimated to be one million [74]. Orphaning has created new social costs for the state and for the household to bear resulting in situations where grandparents struggle to fend for the orphans left behind following the death of their parents $[75,76]$.

The HIV epidemic has been found to decrease gross domestic product, create food security threats, and negatively impact human resources especially the agricultural sector. The Food Agriculture Organisation (FAO) estimated that Zimbabwe lost about $23 \%$ of its agricultural workforce due to the HIV/AIDS pandemic [77]. Exacerbated by the apparent shortages of inputs, poor irrigation and low capitalisation levels the agricultural sector experienced a negative average growth rate of minus $8 \%$ over the past decade [77] and this had obvious negative repercussions on food security and the general health of the nation at large.

\subsection{HIV/AIDS Projections}

Besides the DHS source much of the information on national HIV prevalence in Zimbabwe is derived from surveillance of women attending antenatal clinics. Using the Epidemic Projection Package (EPP) and Spectrum software, declines in HIV-1 disease burden have also been observed in both sentinel surveillance of pregnant women and in the National HIV Estimates process that models all available data [34]. Single digit prevalence has been projected from the year 2016 as shown in Figure 7.

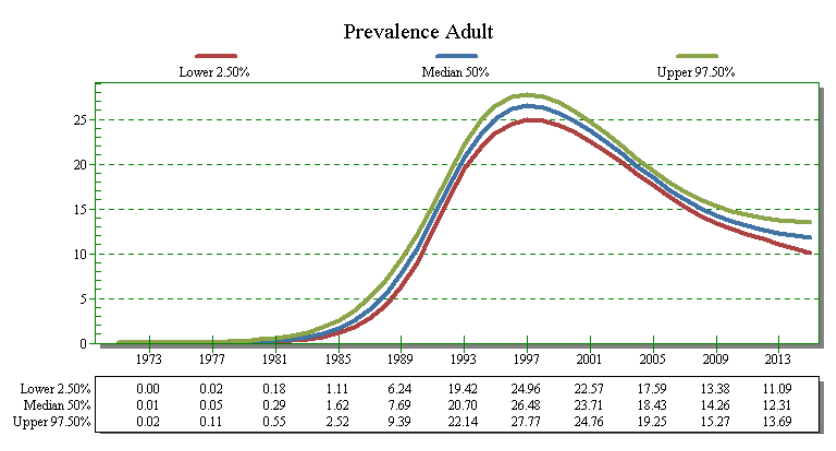

Figure 7. Trends of Adult HIV Prevalence and Projections, Zimbabwe 1970-2015 [78]

\section{Concluding Remarks}

Zimbabwe in one of the few countries in the world currently experiencing a general decline in HIV prevalence, hopefully it continues to fall. Despite the good sign of decline the double digit prevalence is still unacceptably high; therefore, much still needs to be done.The high literacy rate, remarkable behaviour change of the nation and will power of the leadership and the donor community will one day result in an HIV free generation. While dramatic gains in the availability of generic antiretroviral medications have been realised it is important to appreciate that, unless prevention campaigns are more effective and culturally acceptable to the natives then the battle against HIV/AIDS pandemic will be lost. Despite the advancement in biomedical research there is still much we do not know regarding HIV transmission in light of the observed HIV sero discordant couple who in some instances continue to have children. There is need for further research in this field. In the absence of effective prophylactic HIV vaccines, behavior change remains the key to successful prevention efforts.

\section{Reference}

[1] Central Statistical Office H. Census 1992; Zimbabwe National report. 2002.

[2] Zimbabwe National Statistics Agency (ZIMSTAT) and ICF International. Zimbabwe Demographic and Health Survey 201011 2012. Calverton, Maryland, ZIMSTAT and ICF International Inc.

[3] Economist Intelligence Unit. Zimbabwe Country Report. 2008.

[4] Cato Institute. New Hyperinflation Index (HHIZ) Puts Zimbabwe Inflation at 89.7 Sextillion Percent. 2008.

[5] Index Mundi. Zimbabwe unemployment rate. 2009.

[6] DFID. Reducing maternal deaths in Africa. 2008.

[7] WHO. WHO Statistical Information System (WHOSIS). 2008. Geneva.

[8] Mathers CD, Sadana R, Salomon JA, Murray CJ, Lopez AD: Healthy life expectancy in 191 countries, 1999. Lancet 2001; 357(9269):1685-1691.

[9] Sibanda A: A nation in pain: why the HIV/AIDS epidemic is out of control in Zimbabwe. Int J Health Serv 2000; 30(4):717-738.

[10] Ikeogu MO, Wolf B, Mathe S: Pulmonary manifestations in HIV seropositivity and malnutrition in Zimbabwe. Arch Dis Child 1997; 76(2):124-128.

[11] Chimhuya S, Kambarami RA, Mujuru H: The levels of malnutrition and risk factors for mortality at Harare Central Hospital-Zimbabwe: an observation study. Cent Afr J Med 2007; 53(5-8):30-34. 
[12] Ticklay IM, Nathoo KJ, Siziya S, Brady JP: HIV infection in malnourished children in Harare, Zimbabwe. East Afr Med J 1997; 74(4):217-220.

[13] Serdula M: Diet, malnutrition in sub-Saharan Africa. Ann IFORD 1988; 12(2):35-63

[14] United Nations (UN) Department of Economic Social Affairs. World Population Prospects, the 2000 Revision. 2001. Geneva.

[15] United Nations Department of Economic and Social Affairs Population Estimates and Projections Sections of the United Nations Secretariat, World population Prospects: The 2010 Revision. 2010.

[16] Zimbabwe National Nutrition Survey, 2010- Preliminary findings. 2010.

[17] Mapenzauswa S. Zimbabwe Holds First National Meeting on AIDS Crisis", June 15, 2004 . 2004. Reuters NewsMedia.

[18] Dehne KL, Dhlakama DG, Richter C et al.: Herpes zoster as an indicator of HIV infection in Africa. Trop Doct 1992; 22(2):68-70.

[19] Topley JM: HIV infection in Zimbabwe. Arch Dis Child 1988; 63(7):842-844.

[20] McFarland W, Mvere D, Shamu R, Katzenstein D: Risk factors for HIV seropositivity among first-time blood donors in Zimbabwe. Transfusion 1998; 38(3):279-284.

[21] McFarland W, Mvere D, Shandera W, Reingold A: Epidemiology and prevention of transfusion-associated human immunodeficiency virus transmission in sub-Saharan Africa. Vox Sang 1997; 72(2):85-92.

[22] Mertens T: [Modern serologic diagnosis of HIV 1 and HIV 2 infection]. Verh Dtsch Ges Inn Med 1991; 97:375-381.

[23] National blood services Zimbabwe. National blood services Zimbabwe Annual report 2010. 2010. Harare, Zimbabwe.

[24] Denhe K, Dhlakama D, Richter C et al.: Pattern of HIV-infection in Hurungwe district, Mashonaland West, Zimbabwe. Cent Afr J Med 1992; 38(4):139-143.

[25] Mertens T, Tondorf G, Siebolds M et al.: Epidemiology of HIV and hepatitis B virus (HBV) in selected African and Asian populations. Infection 1989; 17(1):4-7.

[26] Tswana SA, Nystrom L, Moyo SR et al.: A sero-epidemiology cross-sectional nationwide study of the prevalence of human immunodeficiency virus in Zimbabwe 1989-1991. Afr J Health Sci 1996; 3(3):96-100.

[27] Zimbabwe 2005-06: results from the Demographic and Health Survey: Stud Fam Plann 2008; 39(3):227-232.

[28] Mbizvo MT, Mashu A, Chipato T et al.: Trends in HIV-1 and HIV-2 prevalence and risk factors in pregnant women in Harare, Zimbabwe. Cent Afr J Med 1996; 42(1):14-21.

[29] Forland F, Eriksen K: [HIV-prevalence in Mutoko, Zimbabwe. A study among pregnant women and patients with sexually transmitted diseases]. Tidsskr Nor Laegeforen 1994; 114(9):10501052.

[30] Obi CL, McAdoo HP, Murray M, Tswana SA, Moyo SR: HIV infection and HIV-1 clades among pregnant women in Harare, Zimbabwe. Cent Afr J Med 1997; 43(7):188-192.

[31] Mbizvo EM, Msuya SE, Stray-Pedersen B et al.: HIV seroprevalence and its associations with the other reproductive tract infections in asymptomatic women in Harare, Zimbabwe. Int J STD AIDS 2001; 12(8):524-531.

[32] Humphrey JH, Hargrove JW, Malaba LC et al.: HIV incidence among post-partum women in Zimbabwe: risk factors and the effect of vitamin A supplementation. AIDS 2006; 20(10):14371446.

[33] Gonese E, Dzangare J, Gregson S et al.: Comparison of HIV prevalence estimates for Zimbabwe from antenatal clinic surveillance (2006) and the 2005-06 Zimbabwe Demographic and Health Survey. PLoS One 2010; 5(11):e13819.

[34] Mahomva A, Greby S, Dube S et al.: HIV prevalence and trends from data in Zimbabwe, 1997-2004. Sex Transm Infect 2006; 82 Suppl 1:i42-i47.

[35] Mahomva A. Zimbabwe PMTCT program, Annual Report. 2007.

[36] Zimbabwe Ministry of Health and Child Welfare. Zimbabwe Ministry of Health and Child Welfare. Zimbabwe National HIV and AIDS Estimates 2007. Harare. 2007.

[37] Bassett MT, Mhloyi M: Women and AIDS in Zimbabwe: the making of an epidemic. Int J Health Serv 1991; 21(1):143-156.

[38] Fowler MG, Melnick SL, Mathieson BJ: Women and HIV Epidemiology and global overview. Obstet Gynecol Clin North Am 1997; 24(4):705-729.
[39] Gregson S, Nyamukapa CA, Garnett GP et al.: Sexual mixing patterns and sex-differentials in teenage exposure to HIV infection in rural Zimbabwe. Lancet 2002; 359(9321):1896-1903.

[40] Latif AS, Katzenstein DA, Bassett MT et al.: Genital ulcers and transmission of HIV among couples in Zimbabwe. AIDS 1989; 3(8):519-523.

[41] Hayes RJ, Schulz KF, Plummer FA: The cofactor effect of genital ulcers on the per-exposure risk of HIV transmission in subSaharan Africa. J Trop Med Hyg 1995; 98(1):1-8.

[42] Simonsen JN, Fowke KR, MacDonald KS, Plummer FA: HIV pathogenesis: mechanisms of susceptibility and disease progression. Curr Opin Microbiol 1998; 1(4):423-429.

[43] Paulo M, Borges AB, Duarte $\mathrm{G}$ et al.: The environmental cofactors in carcinogenesis in high risk HPV/HIV-positive women. Braz J Infect Dis 2007; 11(2):189-195.

[44] Tobian AA, Quinn TC: Herpes simplex virus type 2 and syphilis infections with HIV: an evolving synergy in transmission an prevention. Curr Opin HIV AIDS 2009; 4(4):294-299.

[45] Koethe JR, Chi BH, Megazzini KM, Heimburger DC, Stringer JS Macronutrient supplementation for malnourished HIV-infected adults: a review of the evidence in resource-adequate and resource-constrained settings. Clin Infect Dis 2009; 49(5):787-798.

[46] Dube S, Boily MC, Mugurungi O et al.: Estimating vertically acquired HIV infections and the impact of the prevention of mother-to-child transmission program in Zimbabwe: insights from decision analysis models. J Acquir Immune Defic Syndr 2008; 48(1):72-81

[47] Ferrand RA, Corbett EL, Wood R et al.: AIDS among older children and adolescents in Southern Africa: projecting the time course and magnitude of the epidemic. AIDS 2009; 23(15):2039 2046

[48] Zimbabwe Institute of Development Studies and the UNDP. Zimbabwe Human Development Report. 2003

[49] Matchaba-Hove R. HIV/AIDS in the Zimbabwe defence forces; A civil Society Perspective. In: The Enemy Within. 2005.

[50] Whiteside A, Winsbury R: Vancouver AIDS conference: special report. The role of the military to protect society and themselves. AIDS Anal Afr 1996; 6(4):4

[51] Yeager R: Armies of east and southern Africa fighting a guerrilla war with AIDS. Special report: AIDS and the military. AIDS Anal Afr 1995; 5(6):10-12.

[52] Dalai SC, De OT, Harkins GW et al.: Evolution and molecula epidemiology of subtype C HIV-1 in Zimbabwe. AIDS 2009; 23(18):2523-2532.

[53] Mucheto P, Chadambuka A, Shambira G et al.: Determinants of nondisclosure of HIV status among women attending the prevention of mother to child transmission programme, Makonde district, Zimbabwe, 2009. Pan Afr Med J 2011; 8:51

[54] Sambisa W, Curtis S, Mishra V: AIDS stigma as an obstacle to uptake of HIV testing: evidence from a Zimbabwean national population-based survey. AIDS Care 2010; 22(2):170-186.

[55] Cameron E, Burris S, Clayton M: HIV is a virus, not a crime: ten reasons against criminal statutes and criminal prosecutions. J Int AIDS Soc 2008; 11:7.

[56] Lopman BA, Nyamukapa C, Hallett TB et al.: Role of widows in the heterosexual transmission of HIV in Manicaland, Zimbabwe, 1998-2003. Sex Transm Infect 2009; 85 Suppl 1:i41-i48

[57] Adetunji JA: HIV/AIDS and young age widowhood in subSaharan Africa. J Health Hum Serv Adm 2001; 24(3):259-278.

[58] Strategy for safe medical male circumcision scale up to suppor comprehensive HIV prevention in Zimbabwe. Ministry of Health. 2010.

[59] Halperin DT, Fritz K, McFarland W, Woelk G: Acceptability of adult male circumcision for sexually transmitted disease and HIV prevention in Zimbabwe. Sex Transm Dis 2005; 32(4):238-239.

[60] Bateman C: HIV prevalence in Zimbabwe dropping like a stone. S Afr Med J 2011; 101(1):10-11.

[61] Gregson S, Gonese E, Hallett TB et al.: HIV decline in Zimbabwe due to reductions in risky sex? Evidence from a comprehensive epidemiological review. Int J Epidemiol 2010; 39(5):1311-1323.

[62] Halperin DT, Mugurungi O, Hallett TB et al.: A surprising prevention success: why did the HIV epidemic decline in Zimbabwe? PLoS Med 2011; 8(2):e1000414.

[63] Muchini B, Benedikt C, Gregson S et al.: Local perceptions of the forms, timing and causes of behavior change in response to the AIDS epidemic in Zimbabwe. AIDS Behav 2011; 15(2):487-498. 
[64] Hansen K, Woelk G, Jackson H et al.: The cost of home-based care for HIV/AIDS patients in Zimbabwe. AIDS Care 1998; 10(6):751-759.

[65] Novitsky V, Essex M: Using HIV viral load to guide treatmentfor-prevention interventions. Curr Opin HIV AIDS 2012; 7(2):117-124.

[66] McClellan MK, Patel R, Kadzirange G, Chipatod T, Katzenstein D: Fertility desires and condom use among HIV-positive women at an antiretroviral roll-out program in Zimbabwe. Afr J Reprod Health 2010; 14(2):27-35.

[67] Moyo W, Mbizvo MT: Desire for a future pregnancy among women in Zimbabwe in relation to their self-perceived risk of HIV infection, child mortality, and spontaneous abortion. AIDS Behav 2004; 8(1):9-15.

[68] Mudzviti T, Maponga CC, Khoza S, Ma Q, Morse GD: The impact of herbal drug use on adverse drug reaction profiles of patients on antiretroviral therapy in zimbabwe. AIDS Res Treat 2012; 2012:434171.

[69] Bepe N, Madanhi N, Mudzviti T et al.: The impact of herbal remedies on adverse effects and quality of life in HIV-infected individuals on antiretroviral therapy. J Infect Dev Ctries 2011; $5(1): 48-53$

[70] Monera TG, Wolfe AR, Maponga CC, Benet LZ, Guglielmo J: Moringa oleifera leaf extracts inhibit 6beta-hydroxylation of testosterone by CYP3A4. J Infect Dev Ctries 2008; 2(5):379-383.
[71] Gregson S, Anderson RM, Ndlovu J, Zhuwau T, Chandiwana SK: Recent upturn in mortality in rural Zimbabwe: evidence for an early demographic impact of HIV-1 infection? AIDS 1997; 11(10):1269-1280.

[72] Timaeus IM: Impact of the HIV epidemic on mortality in subSaharan Africa: evidence from national surveys and censuses. AIDS 1998; 12 Suppl 1:S15-S27.

[73] Timaeus IM, Jasseh M: Adult mortality in sub-Saharan Africa: evidence from Demographic and Health Surveys. Demography 2004; 41(4):757-772.

[74] Mangoma J, Chimbari M, Dhlomo E: An enumeration of orphans and analysis of the problems and wishes of orphans: the case of Kariba, Zimbabwe. SAHARA J 2008; 5(3):120-128.

[75] Skovdal M, Campbell C, Madanhire C, Nyamukapa C, Gregson S: Challenges faced by elderly guardians in sustaining the adherence to antiretroviral therapy in HIV-infected children in Zimbabwe. AIDS Care 2011;1-8.

[76] Howard BH, Phillips CV, Matinhure $\mathrm{N}$ et al.: Barriers and incentives to orphan care in a time of AIDS and economic crisis: a cross-sectional survey of caregivers in rural Zimbabwe. BMC Public Health 2006; 6:27.

[77] Kwaramba P. The socio-economic impact of HIV/AIDS on communal agricultural production systems in Zimbabwe. 1997. Harare Zimbabwe, Zimbabwe farmers Union and Friederich Ebert.

[78] Ministry of Health and child Welfare Z. National HIV Estimates 2009. 